\title{
Doomed to repeat the successes of the past: History is best forgotten for repeated choices with nonstationary payoffs
}

\author{
Tim RaKow and Katherine Miler \\ University of Essex, Colchester, England
}

\begin{abstract}
Many everyday tasks involve repeated choices in which past outcomes are used to estimate payoffs but in which present payoffs may differ from past ones. Two experiments with 10 decision problems employing the decisions-from-feedback paradigm examined the choice between two risky options, wherein the payoff probabilities for one option could change over a sequence of trials. Participants either saw the outcomes associated with each option, or additionally were given a "history" summarizing the outcomes of previous trials. Participants adapted quickly to new problems, but adapted slowly to payoff changes. Providing a history improved initial choices, but had a null or negative impact on later ones - although, appropriately, the summary received less weight in later trials. An associative choice model captured changes in preference, but not initial patterns of choice. The findings emphasize the adaptive value of forgetting in unstable decision environments, but illustrate how providing additional relevant information may hinder this.
\end{abstract}

Most research into choice under risk or uncertainty focuses on one-shot decisions. This makes sense, since many of life's more interesting or important decisions, such as accepting or rejecting a proposal of marriage, or deciding whether or not to start a business, occur infrequentlyperhaps only once in a lifetime. Laboratory-based decision research typically provides the participant with a description of the payoffs for each option. This again is entirely reasonable: Describing or predicting patterns of choice requires that the characteristics of each option be known. However, recent investigations of experience-based decision making (EBDM) have emphasized that many everyday decisions are those encountered repeatedly, and that, often, the payoffs for such choices must be estimated from personal experience or by observing the outcomes obtained by those around us. This recognition that oneshot decisions from description are unsuitable models for an interesting subset of real-world decisions is associated with a rise in the number of studies on EBDM (e.g., Erev \& Barron, 2005), reawakened interest in older studies of repeated choice (e.g., Katz, 1964; Myers \& Sadler, 1960) with their roots in the investigation of conditioning and reinforcement learning (e.g., Humphreys, 1939), and a greater appreciation of models of sequential choice (e.g., Busemeyer \& Townsend, 1993). In this article, we extend the EBDM paradigm in two ways, first by considering nonstationary payoff probabilities, and second, by examining the effect of augmenting an individual's experience by providing a summary of past outcomes for the available options. Our primary focus is on how quickly and how successfully decision makers adapt to a new set of payoffs and to subsequent changes in payoffs, and how the provision of additional information (the summary of past outcomes) moderates adaptation.

Our introduction is organized into four sections. First, we establish the value of extending the EBDM paradigm to the case of nonstationary payoffs, emphasizing that this provides an important laboratory model for a number of everyday decisions for which the standard EBDM paradigm is deficient. Second, in relation to this, we discuss three phenomena from judgment and decision research (recency effects in EBDM, probability matching, and the misperception of random sequences). These are usually presented as examples of suboptimal, or irrational, behavior (if stationary payoffs are assumed). However, we argue that these phenomena should lead us to expect that decision makers will often adapt successfully to payoff changes, and, indeed, that such adaptivity may be at the heart of these phenomena. Third, we briefly discuss what can be learned from manipulating the amount of information provided. Finally, we identify the relevant features of some key models of sequential choice, and discuss their relation to our two extensions to the EBDM paradigm.

\section{Extending the EBDM Paradigm to the Case of Nonstationary Payoffs}

Experiments on EBDM take a number of forms, but one common paradigm - "decisions from feedback" - presents participants with a pair of "money machines" that participants play to win or lose money or points (e.g., Barron \&

T. Rakow, timrakow@essex.ac.uk 
Erev, 2003). This is analogous to choosing between two casino gaming machines, switching machines from one play to the next if desired. For a long sequence of trials, the payoffs are fixed in advance for each machine by the experimenter. For instance, Machine A may pay $32 \phi$ with probability 1 but otherwise nothing, but Machine $B$ always pays $3 \phi$. Due to sampling variability, many trials may need to be run before the participant is in a position to estimate that the chance of receiving the best outcome with Machine A is about $10 \%$. The fact that samples of observations may misrepresent the underlying payoff probabilities arguably explains most of the discrepancy in patterns of choice between described decisions and decisions based on modest amounts of experience (Hertwig, Barron, Weber, \& Erev, 2004; Rakow, Demes, \& Newell, 2008). And, of course, observing 6 wins in 60 plays does not guarantee that the participant estimates that the chance of winning is $10 \%$.

Such experiments provide a convenient model for many everyday decisions under uncertainty, such as whether or not to back up the computer, wear a seat belt, or employ a safety device in the workplace. However, the decisionsfrom-feedback paradigm fails to capture an important feature of many of the real-world situations that it seeks to model: namely, that the payoffs for the choice I face now may be different from the payoffs that applied the last time I made this choice. As my hard drive fills up with files, the potential loss from failing to back up increases, and the probability of this loss may increase as my computer ages. As the roads I drive become more crowded, my chance of a serious accident in certain locations may rise. As the machinery in my factory approaches obsolescence, the chance of malfunction increases, perhaps both for the machinery and for the safety device (and possibly at different rates). Such changes in payoff may be gradual or sudden, depending on the situation. Moreover, sometimes there may be no obvious cue in the environment that signals this change or draws our attention to it.

In this article, we adapt the decisions-from-feedback paradigm to consider choices where the probabilities of the outcomes for an option can change from one trial to the next. We consider smooth monotonic changes, such as might be associated with gradual changes in the environment as described above. Although not framed in the language of risky choice, studies of conditioning have considered the effect of changing reinforcement schedules. The most obvious example is the study of "extinction," where the reward for a previously reinforced action is removed (e.g., Humphreys, 1939). The situation that we examine has some similarity to this manipulation of reinforcement rewards. However, we consider risky options that remain risky after a change has occurred, rather than situations where change brings a certain loss to one of the options.

\section{Three Decision Phenomena That Predict Successful Adaptation to Payoff Changes}

A number of robust phenomena in the literature on risky/uncertain choice and risk perception suggest that people might be rather well adapted to identifying and responding to changes in payoffs for decisions under uncertainty. For instance, recency in EBDM, probability match- ing in probability learning experiments, and erroneous beliefs in sequential dependence between outcomes are all either suboptimal or considered irrational. However, if people have good reason to suppose that the decision environment is unstable, such beliefs and behavior could be deemed to be sensible or desirable. We briefly consider each in turn.

Phenomenon 1: Recency in EBDM. Recency effects are often observed in decisions from experience (e.g., Barron \& Erev, 2003; Hertwig et al., 2004). This has been explained in terms of discounting or forgetting initial outcomes. One explanation is that the present opinion about the options is determined by a weighted average of the preexisting opinion derived from prior experience of the options and the outcome of the most recent observation (Hogarth \& Einhorn, 1992; Sarin \& Vahid, 2001). A very similar account is that preference strength is determined by a weighted average of all observed payoffs with recent outcomes receiving greater weight (Busemeyer \& Myung, 1992). Alternatively, people may simply forget initial outcomes, or be more likely to recall recent ones when forming their opinions on the basis of a sample held in memory (Hertwig et al., 2004; Kareev, Lieberman, \& Lev, 1997). When payoffs are stationary (i.e., unchanging over time) such strategies are suboptimal, since the best estimate of the payoffs is obtained from the largest available sample of observations with all observations weighted equally. However, if payoffs can change, recent outcomes are a better guide to present payoffs than are outcomes in the distant past, and payoffs are estimated more accurately if past outcomes are forgotten or discounted. Thus, one interpretation of recency effects observed in the lab is as follows: Participants are applying strategies that have served them well in everyday life (where payoffs often change) to laboratory tasks for which these strategies are not as well adapted (because payoffs are fixed). Recent experiments have shown that recency effects in EBDM disappear or even reverse with small changes in procedure, such as whether the number of observations is determined by the participant or by the experimenter (Rakow et al., 2008; Rakow \& Rahim, in press). This indicates that expectations about the task influence information acquisition and choice. Therefore, participants may sometimes expect payoffs to change over time (even though payoffs are fixed) and may choose accordingly.

Phenomenon 2: Probability matching. In a typical probability-learning experiment, participants must bet on which of a pair of bulbs will light up on each of a sequence of trials. On all trials, the probability of one bulb lighting is fixed at $p$; therefore, the other bulb comes on with probability $(1-p)$. Having learned which light comes on more often, the optimal strategy is to bet on the (same) more frequent option on every trial; but most participants alternate between the options, to the detriment of their winnings from the task. However, in the absence of a belief that the probability is fixed in advance, such behavior is not unwise. Were it really the case that the "better bet" switched between the options, participants ought to search for patterns that might indicate that a change in payoffs had occurred or was about to occur (Gaissmaier 
\& Schooler, 2008; Wolford, Newman, Miller, \& Wig, 2004). Performance in probability-learning tasks can be improved by emphasizing that trials are independent or that probabilities are fixed. For instance, the rate of optimal responding increases when participants are told the actual probabilities for each option (Fantino \& Esfandiari, 2002), when the task is presented as a gambling task rather than a problem-solving task (Goodnow, 1955), and when participants roll a die instead of seeing written sequences of outcomes (Peterson \& Ulehla, 1965). The success of these interventions, which emphasize trial independence and stationary payoffs, implies that participants may not necessarily assume these features to be true when they approach the task.

Phenomenon 3: The misperception of randomness. People often have illusory beliefs about the sequential dependence of successive independent events. In the gambler's fallacy, negative dependence is assumed: A run of heads leads me to believe that tails is due. In the "hot hand" fallacy, a positive dependence is inferred: A sequence of successful shots leads me to believe that a basketball player is temporarily "in form" (Gilovich, Vallone, \& Tversky, 1985; Keren \& Lewis, 1994). In both cases, present payoffs are believed to differ from past payoffs, because event probabilities are assumed to have changed, although this is not in fact the case in these particular instances. However, Ayton and Fischer (2004) have argued that, outside of the casino and the psychology lab, genuinely independent events are rare. For instance, in any situation of sampling without replacement, negative sequential dependencies should be expected; and they will be considerable, if the sample is small. Thus, if life is full of situations that can be exploited by identifying changes in probability over sequences of events, it may be harsh to chastise participants for looking for (and perhaps misperceiving) sequential dependency when none exists. For instance, the "form" of sports teams and individual athletes really can change over time (e.g., see http://thehothand .blogspot.com/), whether from a legal injection of cash or an illegal injection of steroids.

\section{Manipulating the Amount of Information Available to the Decision Maker}

These examples indicate that decision processes might be well adapted to identifying and responding to changes in payoffs, particularly changes in event probability. Therefore, it is interesting, for both theoretical and practical reasons, to adapt the decisions-from-feedback paradigm to consider nonstationary payoffs. However, again for both theoretical and practical reasons, it is valuable to consider how decisions from feedback are influenced by the availability of additional information about past outcomes. This is pertinent because, in many everyday decisions from experience, people also have a record or summary of past outcomes that can inform their decisions. For instance, an employee may record how often her commuter train gets her to work on time, a surgeon may record the number of successes and failures for operations he has performed, or a production engineer may record the number of accident-free days in a factory. Therefore, in our experiments we manipulate whether or not such a summary of historical outcomes is available. We compare choices in which participants rely on experience alone with choices in which participants can rely on both experience and the description of previous outcomes. The latter condition can be thought of as providing participants with a summary of their past experiences. Note that this is different from other investigations that have given experience-based decision makers a description of the objective (i.e., programmed) payoffs (Yechiam $\&$ Busemeyer, 2006). Our paradigm acts as a model for everyday decisions under uncertainty where careful observation and record-keeping provide the most obvious means of estimating payoffs.

\section{Models of Sequential Choice Applied to Nonstationary Payoffs}

Several of the key models of sequential choice can readily be applied to the case of nonstationary payoffs, and it is, therefore, perhaps surprising that they are usually explored and tested in the more restricted case of stationary payoffs. These models fall broadly into one of two classes (already identified above): (1) memory-based sampling models, or (2) belief-updating or associative models.

Kareev's narrow-window model (e.g., Kareev et al., 1997) and the "natural mean heuristic" (Hau, Pleskac, Kiefer, \& Hertwig, 2008) are good examples of memorybased models. The decision maker is assumed to call to mind a sample of observations for each option, which, in the case of repeated choice, may be only a small fraction of the total number of observations. The value of each option is found by averaging outcomes (or by summing outcomes, if equal-sized samples are considered for all options), and the higher value option is then chosen. This approximates an expected value (EV) decision rule: $a p$ proximate because either the observed sample and/or the subsample of outcomes called to mind may be unrepresentative of the outcome distributions for each option.

Many belief-updating or associative models of sequential choice are variants of the Bush and Mosteller (1955) linear learning rule (see Newell, Lagnado, \& Shanks, 2007; Yechiam \& Busemeyer, 2005), according to which the probability of selecting option $\mathrm{A}_{1}$ reflects the decision maker's strength of preference for $A_{1}$ over other options, which updates incrementally trial by trial (i.e., over successive choices), according to the feedback obtained. The probability of selecting option $\mathrm{A}_{1}$ depends on the probability of selecting this option on the previous trial $(t-1)$ and the reward $(d)$ obtained on trial $t-1$, hence

$$
\operatorname{Pr}\left(\mathrm{A}_{1}\right)_{t}=\operatorname{Pr}\left(\mathrm{A}_{1}\right)_{t-1}+\lambda\left[d-\operatorname{Pr}\left(\mathrm{A}_{1}\right)_{t-1}\right],
$$

where $d$ is 1 on rewarded trials and 0 on unrewarded trials, and $\lambda$ is a learning rate parameter that determines the relative weight given to prior preferences and to the most recent reward. This model successfully predicts probability matching and provides a means to instantiate associative strength in associative learning models (Rescorla \& Wagner, 1972). 
At first glance, these two classes of model seem to describe quite different mechanisms. Memory-based sampling posits that choices are determined by a collection of recalled instances. In contrast, with belief updating, actions can be determined by reference to just two values: the first value reflecting prior beliefs or associative strength; the second, the most recent reward. However, the proponents of memory-based models assume, quite reasonably, that recent outcomes are more likely to be sampled than are more distal ones. At this point, both models make qualitatively similar predictions: Recent outcomes will exert more influence on choice than initial observations will. Therefore, patterns of choice will shift to accommodate changes in payoff. However, for either framework, our research paradigm poses key questions: How will the provision of additional information (by way of a summary description of prior outcomes) influence the rate of learning, or affect the relative importance given to initial outcomes and to more recent observations? In turn, how will this affect the decision maker's ability to choose the best option?

\section{EXPERIMENT 1}

Experiment 1 consisted of four decision problems and was designed to examine participants' sensitivity to changes in the probability of outcomes in experiencebased choice. Each problem was presented as a game consisting of 100 "goes," in which the participant had to pick 1 of 2 options on each go. Both options were risky choices, from which participants could win or lose points. The value of the "winning" or "losing" amount of points for a given option remained constant throughout the game, but the probability of a win or a loss could change. In every game, one option, the nonstationary (NS) option, changed over a period of 40 goes, whereas the other option, the stationary (S) option, remained unchanged.

For each game, participants were in one of two conditions, which differed in the amount of information they offered. Participants in the experience-only condition received outcome feedback for their chosen option and for the other option (i.e., forgone payoffs). In the experience-plushistory condition, participants also saw how many times each outcome had occurred for each option (separately). Therefore, these participants received a description of the option payoffs, as well. Since this description reflected observed outcomes rather than objective (i.e., programmed) payoffs, it could be thought of as a frequentist description of the options, based on past outcomes. The comparison between these two conditions provided a comparison between different levels of information provision. The experienceplus-history condition supplied participants with a perfect summary of the outcomes, which should have made it easier for them to identify the better option. However, we also had the possibility of exploring whether accentuating the historical superiority of one option would make participants less inclined to change their preferences.

The rationale for providing forgone payoffs was that without them participants would have had to sacrifice op- timal choices to explore whether a previously suboptimal option had improved since last examined; for instance, when Tversky and Edwards (1966) told participants in a probability-learning experiment that probabilities were nonstationary (although they were not) the number of observations that participants purchased in order to make their decisions increased, thereby decreasing profits. Whereas this dilemma exists in some interesting real-world situations with nonstationary payoffs - such as introducing innovative strategies that may or may not become more effective with time (Denrell \& March, 2001) - we felt that it was unnecessary to expose our participants to it.

The change in the NS option can be a decrease in the probability of a win (Games 1 and 2) or an increase (Games 3 and 4), changes that would be sufficient to alter which option had the higher EV. Therefore, assuming that participants could identify which option had the higher initial EV, we could examine whether participants switched options more readily when a previously "good" option became a "bad" option or when a previously "bad" option became a "good" one.

The changes in win/loss probabilities for the NS option were programmed to occur gradually (over a period of 40 goes), but this change could occur earlier or later in the game, allowing us to explore whether participants' sensitivity to change was moderated by how long the NS option had previously remained unchanged. Models assuming that preference strength was reinforced by each successful outcome would predict that longer periods without change create a stronger preference for an option, making participants slower to reverse their preference (Busemeyer \& Myung, 1992; Busemeyer \& Townsend, 1993; Sarin \& Vahid, 2001). This effect might be accentuated when participants also had a summary description of past outcomes, which would emphasize the historical superiority of the option with the higher average returns.

In Games 1-3, the amount that could be won or lost was the same for each option, so the options were differentiated only by the probabilities of wins or losses. This meant that one option stochastically dominated the other: The probability of a given prize was always greater with one option than with the other, although which option dominated might change in the course of the game. However, in Game 4, both the outcome values and the probabilities differed between the two options, so we could contrast situations in which assessment of win/loss probabilities was sufficient to determine which option was better with a situation (Game 4) in which participants had to weigh up both the amount to be won or lost and their respective probabilities.

\section{Method}

Participants. Forty unpaid volunteers (19 male) with a mean age of 21.4 years $(S D=4.7)$ were tested individually. Almost all participants were students at the University of Essex.

Tasks and Apparatus. Participants completed four computercontrolled games, each consisting of 100 trials. Participants were presented with two on-screen options, described as "money machines." Participants could win or lose points by clicking on an option, and were required to select one of the two machines on each trial. Participants saw the outcome of their choices, so the task was 
an example of "decision making from feedback" (e.g., Barron \& Erev, 2003). Participants were also provided with forgone payoffs (i.e., they saw the outcome for the unselected option), as per Yechiam and Busemeyer (2006).

Each option returned one of two outcomes on every trial: a win (positive points) or a loss (negative points), according to preprogrammed probabilities. For the $\mathrm{S}$ option, these probabilities remained constant for all 100 trials. For the NS option, the probability of a win (and the complementary probability of a loss) altered at some point during the game. The upper panel of Figure 2 on page 991 shows the probability of the better outcome (i.e., a win) for the S and NS option in each game. Changes in the probabilities for the NS option were gradual, the change in probability being .01 per trial. In each game, the two options differed in EV by six points during periods when the probabilities for the NS option were not changing, and were equated for $\mathrm{EV}$ in the middle of the period of change. Therefore, in Games 1 and 2 the NS option was the better option for the first 40 trials (Game 1) or for the first 60 trials (Game 2), but was the option with the lower EV for the remaining trials. In Games 3 and 4, the NS option was the better of the two options for the first 40 trials; but thereafter the S option had the higher EV of the two.

Games 1 and 2 were identical, except that the onset of the change in the NS option occurred at the 21 st trial in Game 1 and at the 41 st trial in Game 2. Games 1 and 3 were designed to be loss-gain "mirror images" of each other: In Game 1, the NS option decreased in $\mathrm{EV}$ from +7 points to -5 points, whereas in Game 3 the NS option increased in $\mathrm{EV}$ from -7 to +5 points (with equivalent variance in outcomes for the two games). The EVs for the two options in Game 3 were the same as for the equivalent options in Game 4 on any given trial. However, in Game 3 the winning and losing number of points was +20 and -10 , respectively, for both options, whereas in Game 4 the S option had different outcome possibilities from the NS option.

The tasks were programmed in RealBasic to run in a Windowsstyle environment, and were performed on an HP Pavilion dv6000 laptop computer.

Design. The primary dependent variables were (1) the number of times that the NS option was picked, and (2) the number of times that participants picked the better option (i.e., the option with the higher programmed EV on any given trial). Each variable was analyzed for five blocks of 20 trials.

Participants were randomly assigned to one of two conditions (20 participants per condition), which differed according to the mode of feedback participants received. In the experience-only condition, participants saw the outcome for the option they chose (i.e., the number of points won/lost) and for the other option (i.e., the number of points they would have won/lost). In the experience-plus-history condition, participants received the same trial-by-trial feedback as other participants, but they also saw the "history" for each machine. This history was in a frequency format, giving the number of times that each outcome had occurred for each machine separately (see Figure 1).

Comparisons between conditions are between subjects. However, because comparisons between games are within subjects, we randomized the order in which participants encountered the four games to counteract order effects.

Procedure. Instructions were deliberately brief to maintain consistency with previously published experiments using the decisionsfrom-feedback paradigm. Participants were simply given the following instructions on a single screen (which also showed an image of two money machines as they would subsequently see them):

You will play a series of games. In each game you will see two "money machines" like those shown below. When you click on a machine you will win or lose points. Your target is to obtain as many points as possible.

In each game you will have 100 "goes" to win points. On each go, you should decide which machine you want to get points from. On each go, the probability of winning or losing points is fixed in advance. However, this probability may change gradually from one go to the next.

When you click on a machine, you will see how many points you obtained. You will also see how many points you would have obtained from the other machine. Pay close attention to this information so that you can decide which machine is the best one to play. You will also see your new points total after every go. In some games it is easier to get a high points total than on others.

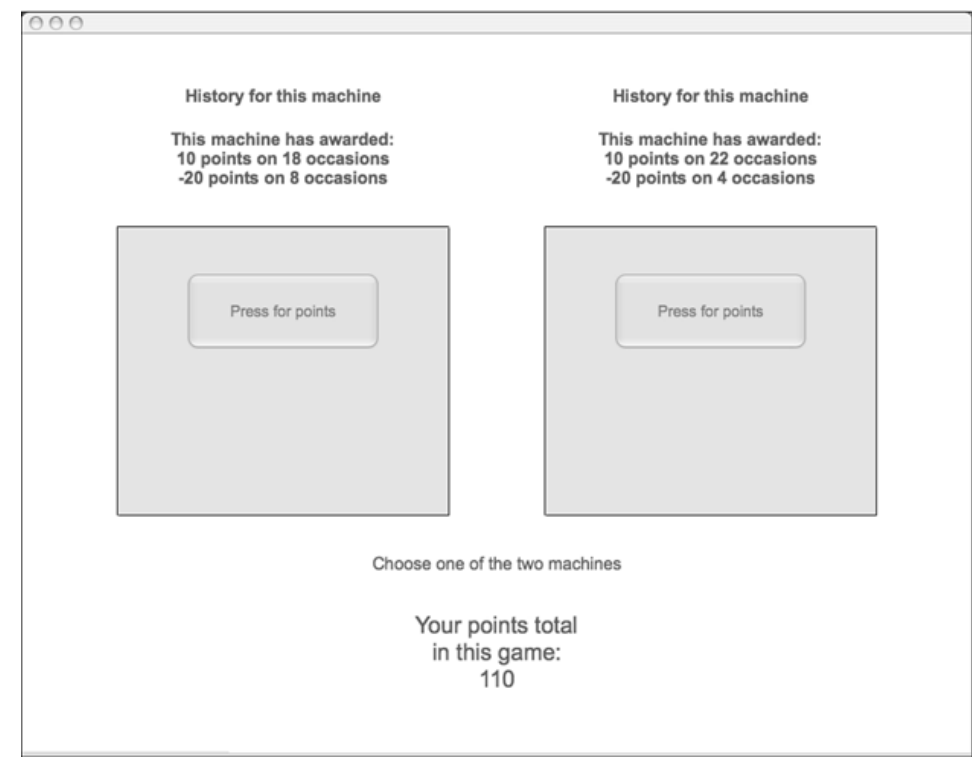

Figure 1. The task as seen by the participants (experience-plus-history condition). 
If you have any questions, ask the experimenter. Press "Ready to begin" to start the first game.

At the start of each game, participants were informed of the number of points that could be returned by each machine. This was designed to ensure that participants were not distracted by the possibility of unknown outcomes. Nothing in the instructions or the experimental setup indicated which machine was the NS or S option (or, indeed, whether there was an NS option in that game). The position of the $\mathrm{S}$ and NS options (left or right) was randomly determined for each new game. The running total of points won for that game was updated after each trial. Participants were told the number of points won at the end of each game, and were given their total for all four games on completion of the fourth game. Participants took about 15 to $20 \mathrm{~min}$ to complete the four games.

\section{Results and Discussion}

The number of NS choices (i.e., the number of times that the NS option was picked) was calculated for each block of 20 trials, as was the number of optimal choices (i.e., the number of times that the better of the two options was picked). The lower two panels of Figure 2 show these results graphed by block and by condition. Graphs showing the number of NS choices illustrate how participants' preferences for the options changed over the course of each game (center panels). Graphs showing the number of optimal choices (lower panels) indicate the quality of decisions (i.e., whether participants were picking the higher EV option more often). ${ }^{1}$ Standard errors are the same for both measures, but for simplicity are only shown on one set of graphs.

Both the number of NS choices and the number of optimal choices were analyzed separately using a pair of $2 \times 5$ (mode of feedback $\times$ block) mixed-model ANOVAs for each game ( $F$ tests and the corresponding effect sizes are reported in Figure 2). Planned comparisons using the LSD procedure were used to examine differences between conditions within each block. Significant differences are shown for the number of optimal choices $\left(^{*}\right.$ or ${ }^{* *}$ in the lower panels). These significant differences also apply to the number of NS choices but are omitted from the center panel for the sake of simplicity. In every case, there was a main effect of block, indicating that preferences for one or the other option (NS vs. S; or, better vs. poorer) altered over the course of the game. The main effect of mode was significant for two analyses. Experience-only participants were less likely than experience-plus-history participants to select the NS option in Game 1, but were more likely than experience-plus-history participants to select the NS option in Game 4. However, in no game was there a significant effect of mode on the number of optimal choices. Thus, on average, participants in one condition were not more successful in the task than were participants in the other condition. Importantly, however, significant interactions for three of the four games for this dependent variable (plus a near-significant effect in Game 3) indicated that the effect of mode was qualified by the stage of the game. These effects are unpacked in detail below.

The lower panels show that providing a history helped participants to identify the better option more easily in the initial trials of each game. In Games 2 and 4, this translated into a significant difference between the conditions in the block when the NS option had started to change (Blocks 3 and 2, respectively). In both cases, participants in the experience-only condition were selecting the better option with greater frequency than in the previous block. In contrast, participants in the experience-plushistory condition were seemingly beginning to respond to the changing probability of a win and were selecting this option less frequently than in the previous block. These differences are particularly interesting. On the one hand, the evidence for which option had been better was still accumulating at a positive rate (the option that had been the better one in previous blocks was still the better one in this block). Providing a history presumably helps participants in the experience-plus-history condition to identify this, even though at this point the EV of this option was declining. (In Game 1, the strength of preference for the better option also continued to increase after the NS option had begun to decline in value, although the effect was smaller than in Games 2 and 4.) On the other hand, the additional information did not increase the rate at which participants' preferences switched during blocks when the NS option was changing. In fact, experience-only participants always decreased their preference for the option that was best in Block 1 as soon as the NS option began to change, and in Games 2 and 4 were seen to change preferences at a faster rate than participants in the experience-plus-history condition (see the center row of panels in Figure 2).

When these initial responses to the two options and the subsequent changes in preference as the NS option altered are combined, there is an important consequence. To appreciate this, consider the block that immediately followed the switch in which option is optimal (e.g., Block 3 in Game 1). In every game, the number of optimal choices was higher for the experience-only condition than for the experience-plus-history condition in this block. This difference was significant in Games 2 and 4 and persisted for the remaining blocks in Games 1 and 4, although in Games 2 and 3 the experience-plus-history participants had "caught up" by the final block. Thus, there seems to be a greater degree of "stickiness" when a history of outcomes is provided; participants were more likely to stick with a previously selected option, even though its EV was no longer greater than that of the other option. Further evidence of greater stickiness when a history is provided was shown by the fact that participants in the experience-only condition alternated more frequently between options (i.e., changed which option they selected on successive trials more often). The average number of alternations per participant per game differed significantly between the two conditions $[M=25.2$ vs. $17.9 ; t(38)=2.03, p=$ $.049, d=0.64]$.

Increasing stickiness or reduced switching between alternatives in the experience-plus-history condition makes sense when one considers what a history might show; take Game 1 as an example. Upon completion of 70 trials, the expected number of wins (10 points) was 51 for the NS option, but 49 for the $\mathrm{S}$ option. Therefore, even though the $\mathrm{S}$ option had been the superior option for 30 trials, a straightforward reading of history shows it to have been inferior. This discrepancy between the present situation 

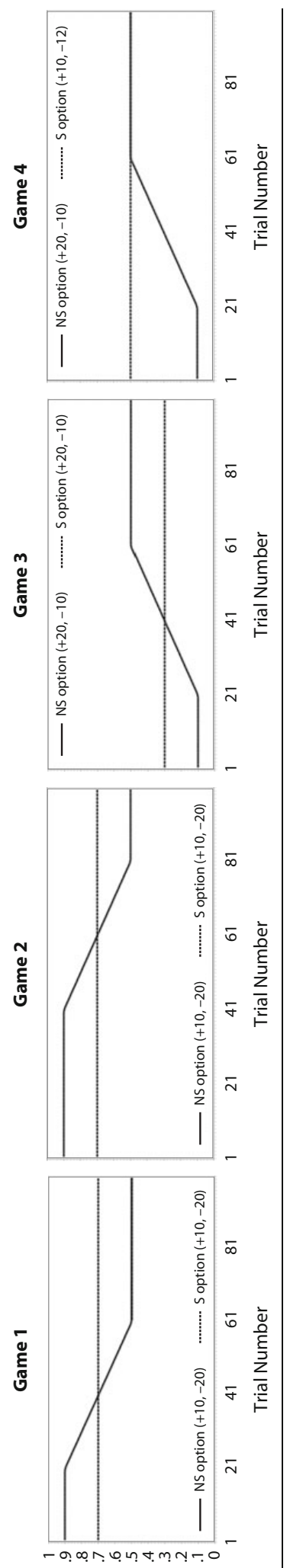

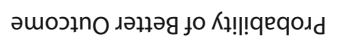
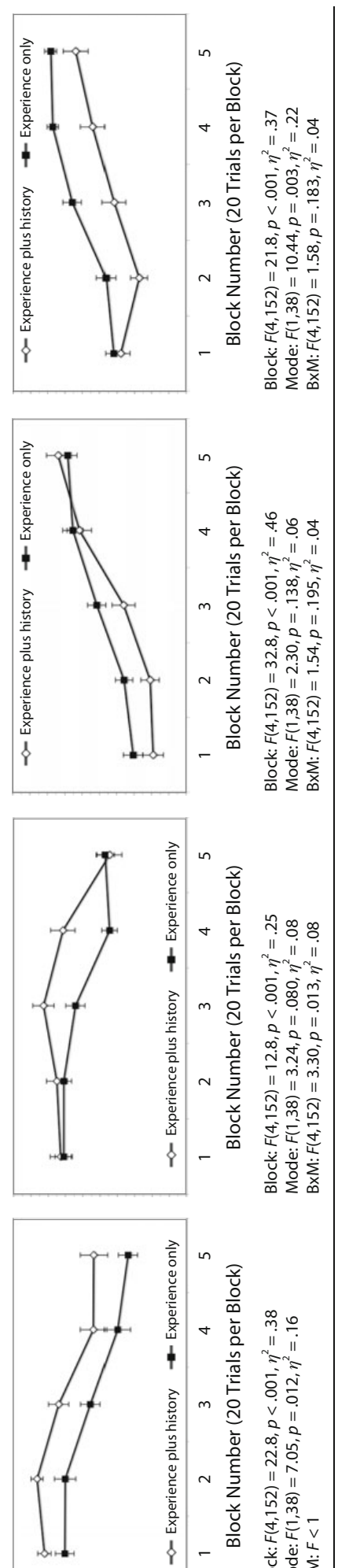

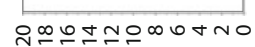

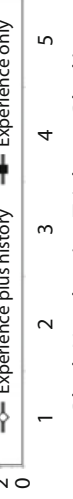

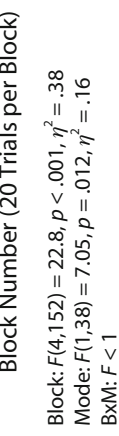

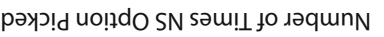

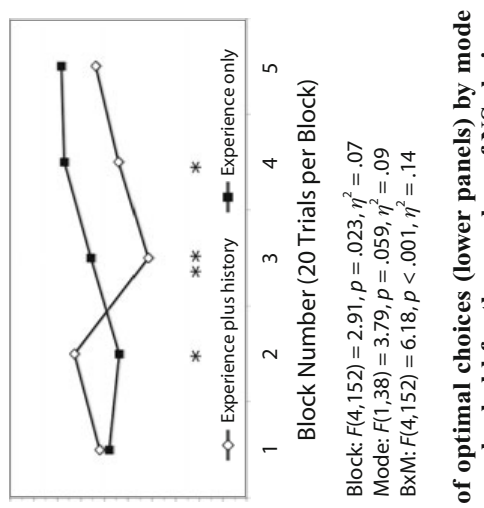

送

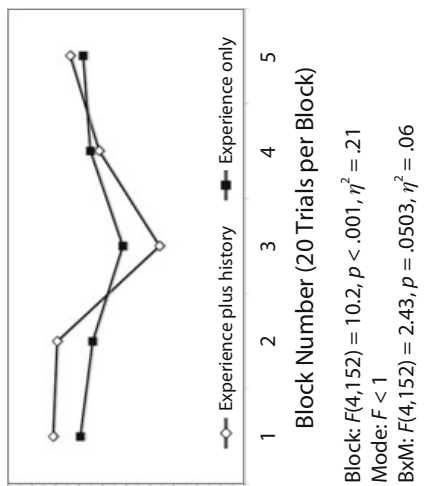

है:

כั

宅宅

过

*

.

命

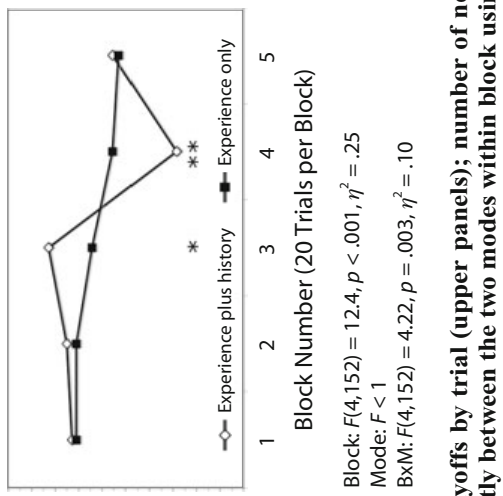

党

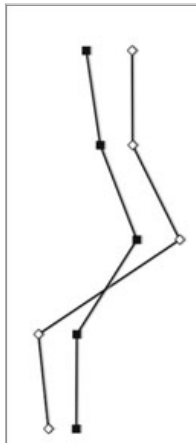

跑

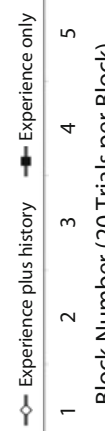

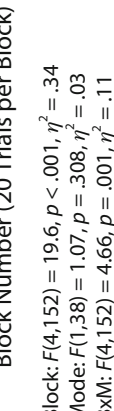

ลั.

宁

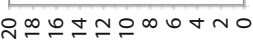

氙

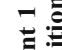

نَّ 
and the accumulation of past history is exacerbated when the period of change for the NS option is delayed, as occurred in Game 2. This explains why this was the one game in which the block $\times$ mode interaction was significant for the number of NS choices. Here history cast the longest shadow, and partially obscured the fact that the NS option was no longer the best one. When a history was provided in Block 4 of Game 2 (when the probability of a win with the NS option fell from .7 to .5), the NS option was selected almost as frequently as it was in Blocks 1 and 2 (when the probability of winning with it was .9). Moreover, in the experience-plus-history condition, in Games 2-4, the preference for the better option was strengthening in the final block, when the NS option was no longer changing, whereas preference had plateaued in the experience-only condition. Thus, providing a history gives no assistance in identifying changing probabilities during a period of change, but it may help to confirm a change after the event.

Inspection of the lowest panel of Figure 2 shows that for Games 1-3, participants were more adept at identifying the better option in Block 1 than in Block 5. This occurred despite the fact that by Block 5 of Game 1, there had been 41 to 60 trials for which the S option had been the better option, and by Block 5 of Game 3 there had been the same number of trials for which the NS option had been superior, far more evidence on which to rely than for Block 1 . This discrepancy between Blocks 1 and 5 in selecting the better option was significant for Game $1[t(39)=3.08$, $p=.004, d=0.74]$ and Game $2[t(39)=3.03, p=.004$, $d=0.67]$, but not for Game $3(t<1)$. In contrast, participants were more adept at identifying the higher EV option in the final block of Game 4 than in the first block, though this was not significant $[t(39)=1.99, p=.054$, $d=0.45]$. Thus, although caution is required, as the features of our games differed on a number of dimensions, these results do suggest an intriguing possibility: It would seem that participants were, in general, more reluctant to switch from a previously "good" option decreasing in value than they were to switch to a previously "bad" option increasing in value. To emphasize this point, note that Games 1 and 3 were almost identical in Block 1 for the number of optimal choices, but differed significantly in Block $5[t(39)=2.40, p=.021, d=0.51]$. It seems odd that participants should be less sensitive to changes in an option that they were selecting (and presumably attending to) more frequently than to one that they were selecting less frequently, yet this is what these data imply. Therefore, we explored this result further in Experiment 2.

Another relevant feature to consider is the fact that the values of the points to be won or lost in Game 4 were not identical for the two options. Therefore, a general increase in the number of optimal choices may simply reflect initial difficulties in identifying the better option when options differ in the amount of points to be won or lost. Certainly, choices are significantly closer to random choice in Game 4 than in Game 3 for Block $1[t(39)=$ $2.48, p=.018, d=0.63]$, and not quite significantly so for Block $2[t(39)=1.95, p=.058, d=0.35]$. It is hard to see how risk attitudes can explain this difference be- tween the games, since the $\mathrm{S}$ option has lower variance in Game 4 than in Game 3. Decreasing the variance (without changing EV) would usually increase the preference for an option (Sharpe, 1964; Weber, Shafir, \& Blais, 2004). However, the pattern here is the reverse of this (initial preferences for $\mathrm{S}$ are higher in Game 3 than in Game 4), which is sometimes the case when dealing with low EV options (see Erev \& Barron, 2005). Therefore, the most parsimonious explanation for this is that when the values of wins or losses are equal across options (as in Games 1-3), simple tallying of outcomes was sufficient to identify the option with the highest EV, whereas in Game 4 more complex strategies were required. These questions are also examined further in Experiment 2.

Finally, we analyzed order or learning effects for each game by analyzing performance in relation to game position (1 through 4, first through last games, respectively). There were no significant effects of game position for the number of points won or for the number of times the better option was chosen. However, there was a significant linear trend $(p=.002)$ for the number of alternations in Game 1; participants decreased their alternation between options with increasing game position (i.e., with more task experience). There was also a significant effect of game position on the number of alternations for Game 4, but there was no significant linear trend.

\section{EXPERIMENT 2}

Experiment 2 extended our analysis of EBDM with nonstationary probabilities. We examined six games of a similar form to those used in Experiment 1, and maintained a between-subjects comparison between "pure" EBDM and EBDM with the additional provision of a summary of past outcomes. Three features were manipulated between the games. First, games were divided equally between those in which the NS option increased in EV, and those in which its EV decreased. This allowed us to follow up on Experiment 1 , where we found surprising differences between cases where participants should switch from a deteriorating NS option and cases where they should switch to an improving NS option. Second, the change in the NS option occurred early in the game for half of the games, but late in the game in the remaining games. This permitted further investigation of "stickiness effects," allowing us to examine the extent to which the accumulated experience of initial outcomes exerts influence on later choices. Finally, games were split equally between those in which the amount of points to be won or lost was the same for each option, and games where this was not the case. This permits a more extensive analysis of how choice is affected by whether or not the possible payouts are identical for both options.

\section{Method}

Participants. The participants were 52 students (13 male) in their penultimate year of high school. All participants were 16 or 17 years of age, except for one 18- and one 19-year-old.

Tasks and Apparatus. The tasks were the same as in Experiment 1, except for the following alterations: In order to examine more games in a testing session, we reduced the number of trials to 
60 per game. The change in the NS option was programmed to begin on either the 21st trial (Games 5, 6, and 8) or the 31st trial, with the probability of a win changing at a rate of .02 per trial, so that the period of change lasted for 20 trials. The points won or lost were either +20 and -10 for both options (Games 5-7), or were $+20 /-10$ for one option and $+36 /-14$ for the other option.

The upper panels of Figures 3A and 3B show the design of each game. In addition to the manipulations to the games described in the previous paragraph, you will see that there were three games with increasing EV for the NS option (Games 6, 7, and 9) and three with decreasing EV. As per Experiment 1, the two options differed in EV by 6 points at the start and end of each game and were equated for $\mathrm{EV}$ at the midpoint of the period of change.

The participants were tested using Macintosh eMac computers.

Design. The design was identical to that of Experiment 1, except that each game was divided into six blocks of 10 trials (rather than five blocks of 20 trials). Random assignment to the mode of feedback conditions resulted in 27 participants in the experience-plushistory condition and 25 in the experience-only condition.

Procedure. The procedure was identical to that of Experiment 1, with participant instructions amended to reflect the change from 100 to 60 trials per game. Participants were tested individually in sessions of a dozen or more. In order to motivate our participants, we informed them in advance that two of them would be randomly selected per session to have their points won converted into money at a rate of $£ 1(\approx \mathrm{US} \$ 2)$ per 1,000 points. These participants were selected and were paid an average of about $£ 3$ each at the end of the 20-min testing session.

\section{Results and Discussion}

The number of NS choices and the number of optimal choices were calculated within each block of 10 trials for each game. These dependent variables were analyzed using $2 \times 6$ (mode of feedback $\times$ block) mixed-model ANOVA, and with planned comparisons for the effect of mode within each block, using the LSD procedure. The results for each game are shown in Figures 3A and 3B.

Differences between the experience-only and experience-plus-history conditions are less marked than in Experiment 1. We can identify two likely causes for this. First, there were fewer trials per game than in Experiment 1 . This gave participants less opportunity to learn about the environment, which would be expected to add uncertainty to their preferences, making responses more erratic. With fewer trials, all else being equal, measurement is also noisier, which, in turn, decreases statistical power. Second, this cohort of participants was not recruited from our usual participant pool, and we strongly suspect that they were less motivated than were the participants in Experiment 1.

However, where significant differences between the conditions occurred, they were entirely consistent with the pattern of results found in Experiment 1. Providing a history provided significant assistance with the early identification of the better option in Games 5 and 7, but significantly hindered identification of the better option in later trials in Game 9 (and, to a lesser degree, in Games 5-7).

We did not see the same tendency toward better initial responding than final responding that was evident in Experiment 1 . This may be due to a key difference between the two experiments. The switch in which option was optimal typically occurred earlier in Experiment 2 than in Experiment 1. Consequently, there was less cumulative reinforcement for the initially optimal option in Experi- ment 2. Therefore, initial preferences should have been weaker and should have exerted less influence on later preferences (Busemeyer \& Myung, 1992; Busemeyer \& Townsend, 1993; Sarin \& Vahid, 2001). Inspection of the graphs shows that initial preferences for one option over another were not as strong as in Experiment 1. Also, the effect sizes for the effect of block on the number of NS choices show that participants were not as responsive to changes in probability. Only in Game 7 did participants make significantly more optimal choices in Block 1 than in Block $6[t(51)=2.91, p=.005, d=0.61]$. This difference was close to significant in the same direction for Game $9(p=.053)$, but there was a similarly sized effect in the opposite direction in Game $10(p=.072)$.

The most direct test of the effect of altering when the period of change occurs for the NS option can be done by comparing Games 6 and 7. The only difference between these two games is when the NS option changes (later, in Game 7). To examine the impact of changing probability, we examined Blocks 2 and 5 of Game 6 and Blocks 3 and 6 of Game 7, the blocks that immediately precede and follow the period of change in the NS option. The change in the number of optimal choices was greater for Game 6 than for Game 7, an interaction that approached significance when analyzed with a $2 \times 2$ within-subjects ANOVA $[F(1,51)=$ $\left.3.26, p=.077, \eta^{2}=.06\right]$. Thus, there was again some evidence of greater stickiness when the period of change for the NS option occurs later in the game.

In contrast with Experiment 1, there was no sign of greater sensitivity to increases in the EV of the NS option than to decreases in EV. If anything, the opposite was true; this aligned with the expectation that it ought to be easier to identify changes in an option that one is attending to. As identified above, the only game where performance in identifying the better option was worse at the end than at the start was one in which the NS option increased in EV (Game 7). Furthermore, performance in the final block was better for Game 5 (decreasing EV for NS option) than for Game 6 (increasing EV), and better for Game 10 (decreasing EV) than for Game 9 (increasing EV). The latter of these two differences was significant $[t(51)=2.09$, $p=.042, d=0.42]$.

One noteworthy result from Experiment 2 is the lack of a clear preference between the options in Games 8-10, where the points to be won or lost differed between the two options. In Game 8, the mean number of times a given option was chosen never differed significantly from 5 (i.e., neutrality). This was also true of Game 10, though there was a nearly significant preference $(p=.0503)$ for the $\mathrm{S}$ option in the final block of this game. In both these games, the NS option initially had the higher EV of the two options. In Game 10, the NS option also had high variance, for which habitual risk aversion would predict reduced preference; however, in Game 8, the $\mathrm{S}$ option had high variance, and the same lack of clear preference was found. Therefore, the lack of clear initial preferences seems to be more closely tied to the difficulty of identifying the better option than to risk attitudes. Moreover, preferences changed little over the course of the game in Games 8-10, and much less so than in Games 5-7, 


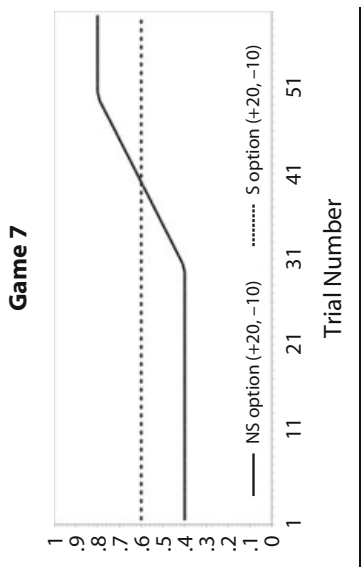

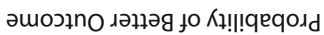

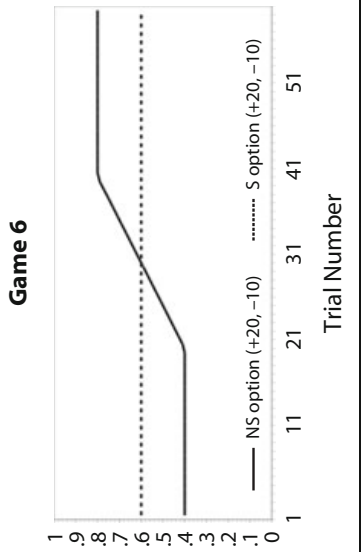

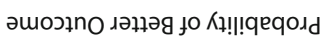

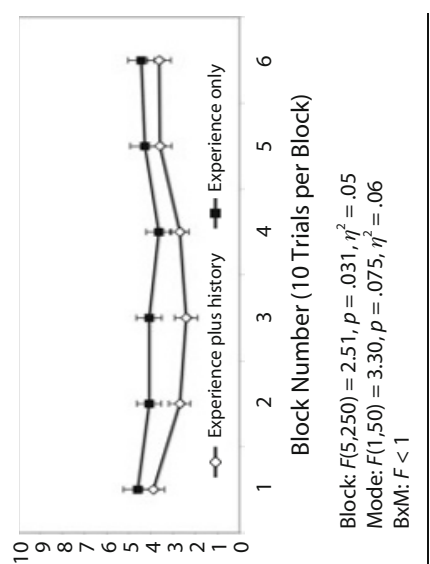

pəyग!d uo!̣do SN səu! $\perp$ fo גəqunN
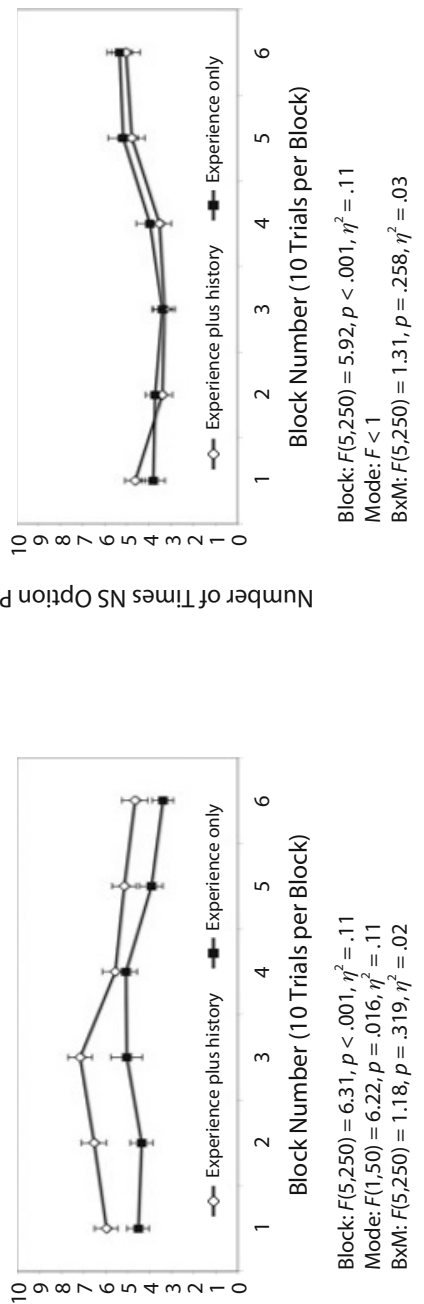

рәуग!d Uo!̣dO SN Səu! $\perp$ fo גəqunN

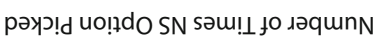

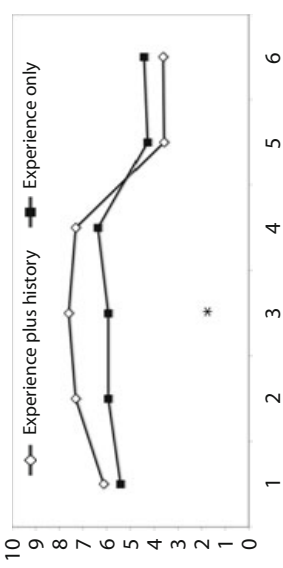

हैं

긍

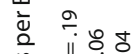

$+\frac{n}{. \underline{T}}=11$

$\bar{c}^{2}=$

으 옹ำ

$m$ 范

है

N

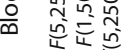

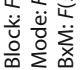

\&

:

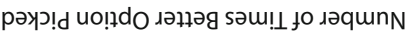

范

ลิํํㄹ

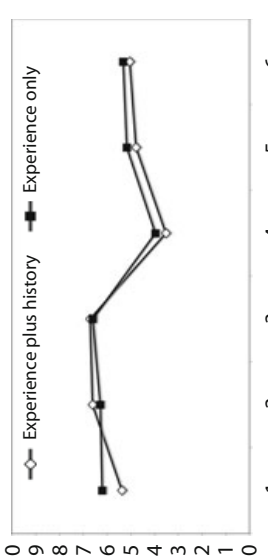

है v

눈

合亲

$\ln \frac{\bar{x}}{0}$

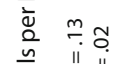

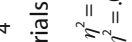

홍ㅎㅇ

$=\underset{v}{*}$

$m$ वे o

至

$\sim$ 흠

寅宫

赑色的

近它

恙

䜦

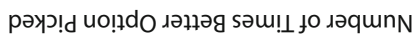
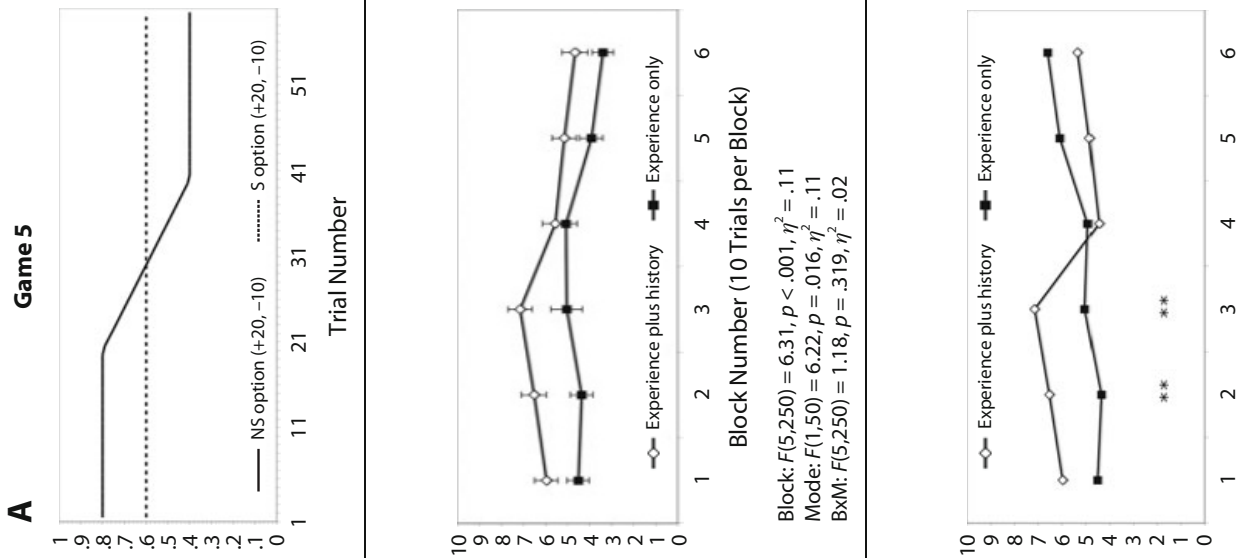

要

突

गับ

苋

$\frac{0}{0}$

离

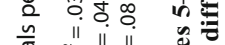

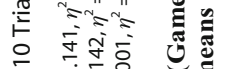

ii

है

II

高 


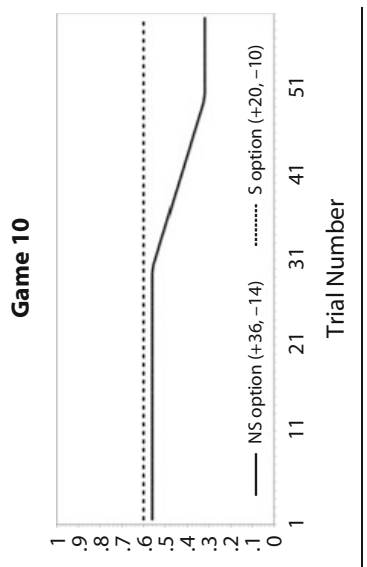

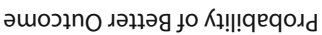

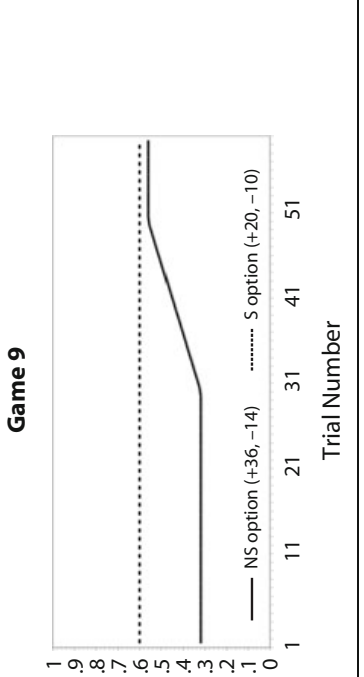

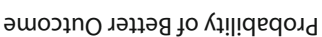

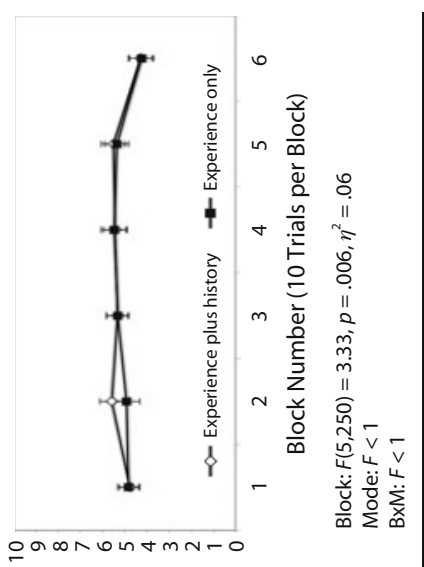

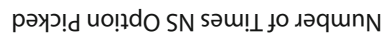

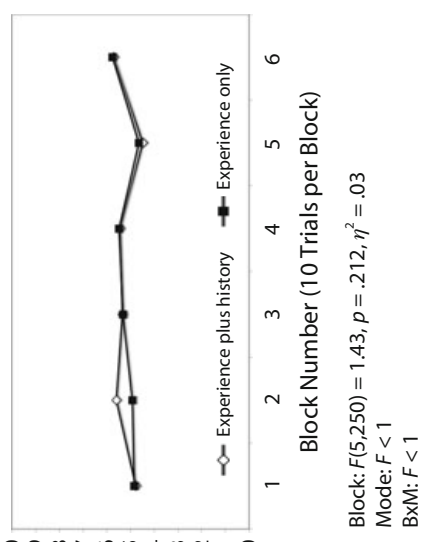

으은

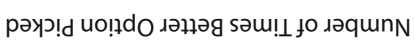

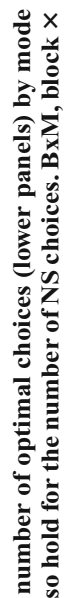

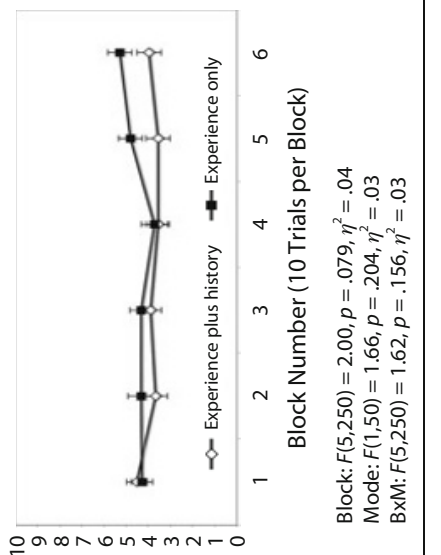

pəyग!d uo!!do SN Səu! $\perp$ fo גəqunN

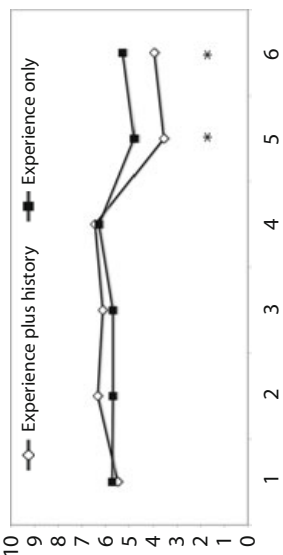

on $\infty \wedge$ intm $m$ -

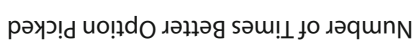

공

¿ $\stackrel{m}{\sim} m$

$\frac{\sqrt{0}}{n}$ il 11 i

i. $2=$

응

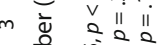

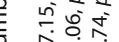
กำ 商官员

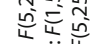

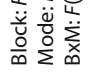

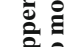

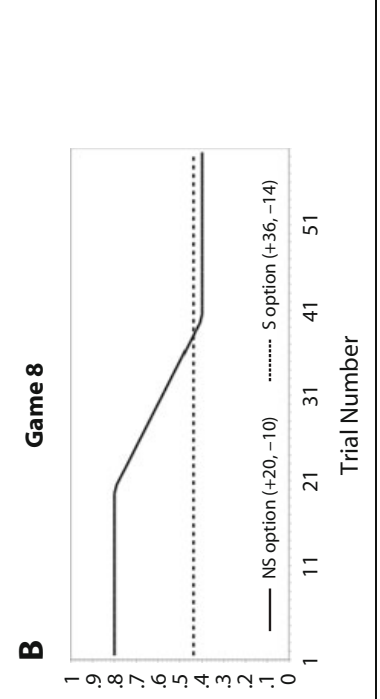

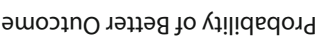

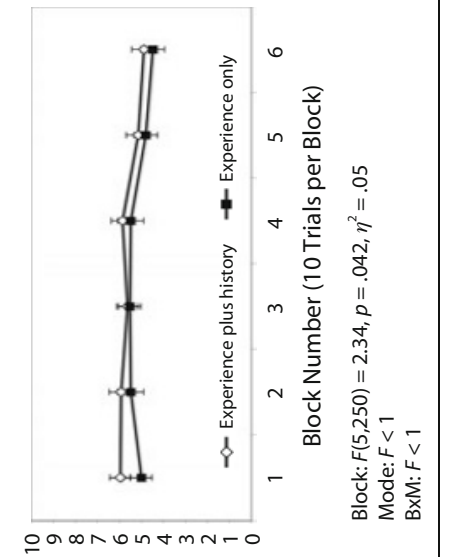

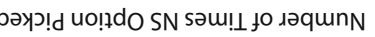
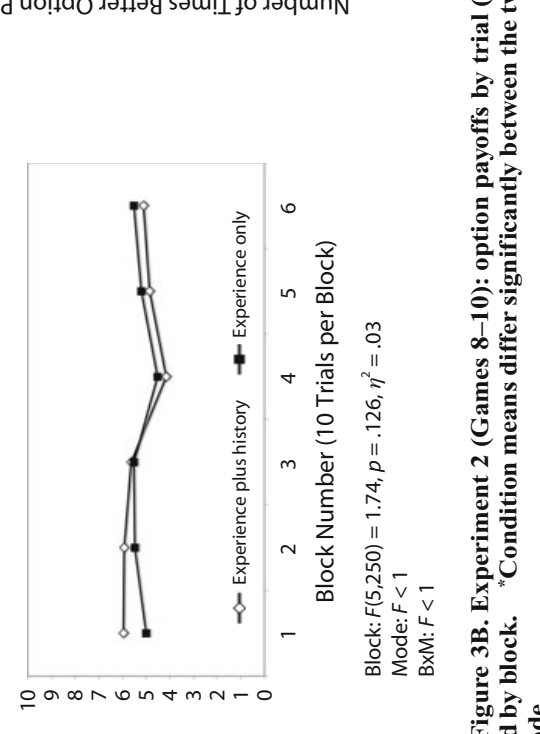

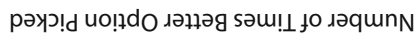


the variance accounted for by the main effect of block in Games 8-10 being about half of that for Games 5-7. Therefore, not only does having different possible outcomes make it harder to identify which option is best, it also makes it harder to identify changes in probability when they occur.

Order or learning effects were examined separately for each game, as in Experiment 1. Again, there were no significant effects of game position (1 through 6, first to last) for the number of points won, or for the number of times that the better option was picked. However, in Games 3, 4, and 6 , there was a significant linear trend for the number of alternations; participants with more task experience alternated less frequently between the options in each case. There was also a significant effect of game position on alternation in Game 1, but the linear trend was not significant. Excessive alternation between options is a suboptimal choice strategy in this task (cf. "matching" in probability learning). Therefore, this tendency for reduced alternation represents a gradual improvement in task performance with task experience (for a similar result in probability learning, see Shanks, Tunney, \& McCarthy, 2002).

\section{GENERAL DISCUSSION}

\section{Stickiness Effects}

The general pattern in these experiments is relatively fast initial adaptation to payoffs at the beginning of a game, but relatively slow adaptation to subsequent changes in payoff. Thus, consistent with studies of conditioning, responses learned under conditions of variable reinforcement are resistant to extinction (Humphreys, 1939). Initial and later responding may reflect different learning strategies, such as those Erev and Barron (2005) characterize as "fast-best-reply" and "slow-best-reply," respectively. The result is that initial choices based on limited experience are often more successful than are later choices based on much more experience of the final payoffs. This aligns with what Gaissmaier, Schooler, and Rieskamp (2006) found when they suddenly changed the event probabilities in a probability-learning study. It can take a long time to overcome the adverse effects that a change in the environment can have on performance. The implication is that even if they are not retained in memory, initial observations exert a powerful impact on later choices. Therefore, choice cannot simply be determined by a small sample of recent outcomes. However, it is also important to note that preferences do change. Therefore, choice cannot depend only on a small sample of initial outcomes. The implication is that beliefs are updated, presumably by a process of gradual adjustment (Busemeyer \& Myung, 1992; Hogarth \& Einhorn, 1992; Sarin \& Vahid, 2001), although the rate of adjustment is not constant.

Initial rates of adaptation, and subsequent changes in choice behavior, were both affected by providing participants with a summary history of their experience, updated after every trial. The provision of this description generally increased initial learning. Friedman and Massaro (1998) reported a similar positive effect for providing a history of similar trials in a (binary) categorical judgment task. However, providing a history of outcomes did not enhance (and sometimes slowed) the immediate adaptation to changes in payoffs. In effect, initial outcomes that were best forgotten or ignored were retained in memory. This tension between learning and forgetting is captured in Busemeyer and Myung's (1992) adaptive network model, in which both the rate of learning about payoffs and the rate of forgetting determine preference strength. Our history manipulation increased learning rates (at least initially), but, by effectively reducing the forgetting rate and/or slowing the subsequent learning rate, left our experience-plus-history participants sluggish in response to a change in payoff probabilities. Providing additional accurate and easy-to-understand information proved to be a double-edged sword, helping with one aspect of the task but not with another; and it serves as another powerful example of the potentially adaptive value of forgetting (see Luria, 1968/1987; Schooler \& Hertwig, 2005).

\section{Variability Effects}

Numerous studies find that, holding EV constant, increasing the variance in returns decreases the attractiveness of a positively valenced option but increases the attractiveness of a negatively valenced one (Weber et al., 2004). This is simply described as risk aversion for gains and risk seeking for losses, and is incorporated into many models of risky choice (e.g., prospect theory; Kahneman \& Tversky, 1979). Studies of EBDM have identified another variance-related effect: the payoff variability effect. As the variance of options increases (holding EV constant), the discriminability of alternatives decreases, and preference moves in the direction of random choice (see Busemeyer \& Townsend, 1993; Erev \& Barron, 2005; Myers \& Sadler, 1960). Our results do not fully align with these effects. Decreasing discriminability did move initial preferences toward random choice in Games 8-10, but increasing discriminability had the same effect in Game 4. In Games 8-10, positively valenced options both increased and decreased in popularity with increased variance (in comparison with Games 5-7), although perhaps payoff variability was the dominant effect here. Moreover, in Game 4, the lower variance of the S option (in comparison with Game 3) did not increase its attractiveness.

Gonzalez-Vallejo (2002) provided an insight consistent with these results. She and others have pointed to the importance of the comparability of attributes as an important driver of choice behavior. In Games 4, 8, 9, and 10, where the two options differed appreciably from each other in variance, they also differed according to the number of points that could be won; in other words, comparing the value attribute (i.e., points) of the options in these games was less straightforward than in other games, where both options returned identical numbers of points in the case of either option returning a win (or returning a loss). For instance, in Game 5, the NS option initially "beats" the S option by 30 points on $32 \%$ of occasions, "loses" by 30 points on $12 \%$ of occasions, and "ties" the remaining $56 \%$ of the time. Strategies like win-stay and lose-shift provide a relatively straightforward means of evaluating and reacting to such choices. However, in Game 8, which shares 
most of its characteristics with Game 5, a more complex set of asymmetrical relative outcomes arises. It is possible for the NS strategy to "win" by 34 points or 4 points and to lose by 16 points or 46 points. The resulting difficulty in comparing outcomes explains why initial (and, often, final) preferences are pushed in the direction of random choice in games with unequal outcomes. The lack of clear preference for these games is also apparent in the alternation rates: With unequal outcomes, participants are more liable to switch between options on successive trials. In Game 4, the mean number of alternations between options is 28.3, whereas for Games 1-3 it is 16.8, 17.9, and 23.2, respectively. In Games 8-10, the mean number of alternations is $21.5,24.0$, and 22.5 , but is consistently lower in Games 5-6, at 17.7, 18.3, and 18.1.

\section{Direction-of-Change Effects}

We were intrigued by the possibility in Experiment 1 that participants responded more readily to improvements in a less favorable option than to decrements in a more favorable one. This was not corroborated in Experiment 2, where the opposite pattern was more common, which was more in line with our expectations. Even though forgone payoffs were provided, we anticipated that participants would attend more closely to the (favorable) option that attracted more of their choices. It would be more natural to spot a fall in returns from an option being played regularly than to spot increases in returns for an option being played occasionally.

One contributory reason for the rather better responsiveness to payoff change in Experiment 1 than in Experiment 2 could be that in Experiment 1, the NS option switched from positive to negative EV, or vice versa, whereas it remained positive in Experiment 2. For instance, Bereby-Meyer and Erev (1998) found quicker learning in a probability learning experiment when payoffs were $+2 /-2$ rather than $+4 / 0$ or $0 /-4$. The natural reference point of zero EV should make it easier to spot that a payoff has moved, particularly if - as was the case in our experiments - participants see a running points total that makes it easy to see whether points are decreasing or increasing. Nonetheless, exactly why negative-to-positive changes prompted less sticky behavior than positiveto-negative changes in Experiment 1 warrants further investigation.

\section{Modeling the Choice Data}

We used a version of the Bush-Mosteller linear learning rule (see the beginning of this article) to model the data of Experiment 1: $\operatorname{Pr}\left(\mathrm{A}_{\mathrm{NS}}\right)_{t}=\operatorname{Pr}\left(\mathrm{A}_{\mathrm{NS}}\right)_{t-1}+\lambda[d-$ $\left.\operatorname{Pr}\left(\mathrm{A}_{\mathrm{NS}}\right)_{t-1}\right]$, where $\operatorname{Pr}\left(\mathrm{A}_{\mathrm{NS}}\right)_{t}$ is the probability of selecting the NS option on trial $t$. The reward value, $d$, was computed as a linear transformation of the difference between option payouts on a given trial (NS-option payout minus S-option payout). This was calculated separately for each game. Thus, $d$ was 1 for the maximum reward (highest relative gain) and 0 for the minimum reward (highest relative loss). This was a reasonable way to represent reward value, because participants knew the possible payouts in advance and saw the payouts for both options on any given trial. The learning rate parameter, $\lambda$, was fit separately to group-level data for each condition. This was determined by minimizing the mean square error, assuming $\lambda$ to be fixed across all 100 trials of all four games.

The optimal value of $\lambda$ of .46 in the experience-only condition of Experiment 1 gave an excellent fit to the profile of the data. In other words, changes in preference between the two options were well predicted by the model. The correlation $(r)$ across trials between the expected and actual proportion of times that the NS option was chosen was $.89, .83, .87$, and .87 for Games $1-4$, respectively. The best-fitting value of $\lambda$ in the experience-plus-history condition was .36. The lower value of $\lambda$ implies that the most recent reward received less weight than did earlier payouts when a history was provided. In other words, participants in the experience-only condition were generally more sensitive or responsive to the most recently observed outcome than were participants in the experience-plushistory condition. However, it is important to note that our modeling held $\lambda$ constant across all 100 trials, and that the data show that the reverse pattern holds in the first few trials (greater sensitivity to recent reward values in the experience-plus-history condition). The model provided a good fit to the data in terms of describing changes in preferences in the experience-plus-history condition (though not as good as the fit for the experience-only condition). The correlation between the expected and actual proportions of NS choices was $.81, .76, .88$, and .79 for Games $1-4$, respectively. ${ }^{2}$

Thus, the Bush-Mosteller (B-M) rule, which has successfully served as the basis for several models of associative learning, provides a good description of how participants switched preferences between options in Experiment 1, but two deficiencies in this model may be instructive.

First, whereas the B-M rule accurately accounts for changes in patterns of choice, it is not particularly accurate in predicting the absolute proportion of times that the NS option is chosen. Specifically, for Games 1-3, the B-M rule predicts proportions closer to .5 in Block 1 than are found to be in the data (mean discrepancy $\approx 2$ ). The reverse discrepancy was observed in Game 4, where the possible payouts differed between options. This difficulty in modeling initial choices, followed by comparative success in modeling changes in preference, points to an intriguing hypothesis: Decision processes in initial trials may be qualitatively different from those in later trials. For instance, when only a few outcomes have been observed, memorizing or tallying all outcomes should provide a fairly accurate means of determining the best option to date, but with increasing information such a strategy becomes more difficult to implement and/or may be discarded as inappropriate if the decision maker expects that the decision environment may be changing. At this point, a shift to a belief-updating strategy may occur. This hypothesis warrants investigation with new data.

Second, as indicated above, the B-M rule predicts preference shifts more accurately for the experience-only condition than for the experience-plus-history condition. Thus, we considered what additional mechanisms might 
be at work when a summary of past outcomes is provided. We examined this using an information-integration approach (for examples of this approach in decision research, see Anderson \& Shanteau, 1970; Birnbaum \& Navarrete, 1998; Ebbeson \& Konecni, 1975). We found that the fit to the data in the experience-plus-history condition could be improved by assuming that the information from the summary is "averaged" together with the output of the B-M learning rule. Specifically, on each trial we took a weighted average of the probability generated by the B-M rule condition $\left[\operatorname{Pr}\left(\mathrm{A}_{\mathrm{NS}}\right)\right]$ and the proportion of participants in the experience-plus-history condition for whom the cumulative value (from all previous trials) of the NS option exceeded that of the S option. For this, we used the B-M model for the experience-only condition to avoid overfitting, thereby combining beliefs in the absence of a summary, together with the information contained in the summary. This approach mimics successful models of advice taking, where an individual integrates his personal belief with external advice by means of a weighted average of the two (Biele, Rieskamp, \& Gonzalez, 2009; Yaniv, 2004; Yaniv \& Kleinberger, 2000). In our data, the B-M model provides a measure of the strength of personal belief, and the summary serves as "advice" concerning which option is "in the lead." The best results were achieved by assuming that the weights assigned to the two sources of information change over time. This reflects the fact that the discrepancy between the two conditions generally diminishes over the course of each game. On trial number $t$ we assigned a weight of $t$ to the data generated by the B-M model and a weight of $(100-t)$ to the data taken from the summary. The resulting expected proportion of NS-option choices was highly correlated with the actual proportions: $r$ of .88, .75, .91, and .82 for Games 1-4 (i.e., an improvement on the B-M rule for three of the four games, resulting in a fit comparable to the experience-only condition).

We accept that this latter modeling exercise is post hoc, and is therefore better suited to generating than to testing a hypothesis. However, it does emphasize that the impact of providing a summary diminished over time (i.e., with increasing experience). Given the potentially diminished value of the summary in the middle and later part of the game discussed above, such behavior is adaptive. It allows participants in the experience-plus-history condition to avoid being completely caught out by the discrepancy between cumulative (past) outcomes and more recent outcomes. Here too, we can draw parallels with two findings from the advice literature: First, novices weight advice more heavily than experts do (Harvey \& Fischer, 1997); and second, the weight placed on advice increases with the perceived expertise or credibility of the advisor (Sniezek \& Buckley, 1995). Similarly, in our experiments, participants in a new environment (i.e., "novices") were more willing to rely on an external source of information (the summary), but as the credibility of that source diminished, participants gave it less weight.

\section{Applications}

One of the real-life situations that inspired our experimental investigation is the dilemma associated with "learning curves" in surgical innovation. For instance, Bull, Yates, Sarkar, Deanfield, and de Leval (2000) discussed the introduction of a new operation (the arterial switch) for a serious congenital heart defect (transposition of the great arteries), where there was a previously triedand-tested procedure (the Senning operation). Initially, survival rates for the arterial switch procedure were below those for the (preexisting) Senning operation. However, over time results for the arterial switch improved to be better than those for the Senning; this new operation replaced the old one as the standard technique for managing neonates with transposition of the great arteries. Our results indicate that unaided judgment may detect such changes, but that it is far from guaranteed to do so. However, our results also indicate that simple procedures for tracking performance may hinder rather than help, in some circumstances, in the identification of improvements in outcome. Denrell and March (2001) discussed the possibility that innovations are too often discarded before the experience necessary to guarantee their success has been gained. Our results caution against a related possibility - that sufficient experience really has been gained to guarantee higher levels of success but the innovation is discarded anyway, since initial failures loom too large in the evaluation of present performance to permit a positive evaluation.

Not only do we need to know when an option has improved, we need to know when things have deteriorated. Also in the context of surgery, Kunadian et al. (2008) have illustrated how cumulative results can be used to test for important differences in the performance of different surgeons. However, what our results show is that focusing on cumulative performance can obscure the nature of differences in present performance. Therefore, monitoring whether a previously successful surgeon is now performing below par requires a system that discounts or "forgets" performance in the more distant past (see de Leval, François, Bull, Brawn, \& Spiegelhalter, 1994). Numerous techniques and systems of this kind have long been available and are widely used in quality control in all manner of industries and endeavors, including medicine. However, what our results emphasize is that, for some purposes (such as identifying changes in outcomes), succumbing to the temptation of simpler monitoring procedures may be worse than having no formal system at all.

\section{Extensions}

We believe that decisions from experience with nonstationary payoffs represent an important experimental paradigm that provides a good laboratory model for an interesting class of everyday decisions. This paradigm provides a valuable new testing ground for new and existing descriptive models of choice.

Even within the class of problems and set of experimental conditions that we studied, there is clear scope for further experimentation. The impact of the direction of change warrants further investigation, as does whether reversing the valence of the nonstationary option accentuates the change in payoffs. Further work is required to disentangle the effects of option variance on the attractiveness, discriminability, and comparability of options. Another area for 
investigation is the number of trials required for successful adaptation to the environment. We have suggested that the limited number of trials per game contributed to the less successful adaptation to the task in Experiment 2. It should, therefore, be instructive to undertake more extreme manipulations of the number of trials for which payoffs remain stationary prior to an alteration in the payoffs.

Looking beyond the present experimental set-up, we could consider the case where forgone payoffs are not given (as is true of many real-life decisions). Indeed, several recent investigations of EBDM illustrate that the precise nature of the feedback that a participant receives is important (Jessup, Bishara, \& Busemeyer, 2008; Newell \& Rakow, 2007). Intuitively, we might expect such manipulations to be especially important for nonstationary payoffs. Future experiments could also present some participants with a moving window of history summarizing only the last $N$ outcomes for each option. Depending on the value of $N$, we could presumably increase or decrease the rate of adaptation to initial payoffs and to changes in payoffs, and, with the right value of $N$, move participants toward more optimal responding. This is a valid and interesting manipulation for future experimentation, although we note that in everyday life there is rarely a benevolent experimenter who can advise us on the optimal amount of experience to draw upon. One important question for such a study would be whether the impact of a summary diminishes over time (as indicated by our modeling). For, whereas this is adaptive for the paradigm studied in this article (where cumulative outcomes over a long period could be misleading), such is not the case where a summary refers to only the most recent outcomes. It would also be valuable to extend the paradigm to consider options with three or more possible outcomes. This would also open up the possibility of changing outcomes (as well as changing probabilities, as we have done).

We have seen that participants adapt more quickly to a new decision environment than to changes within an existing one. Providing additional information in the form of the history of outcomes proved to be a double-edged sword, helping participants to improve payoffs for their initial choices, but leaving them underperforming in the period following a change in the payoffs of one of the options. Our results illustrate the adaptive value of forgetting. Sometimes the lessons of history really are best forgotten.

\section{AUTHOR NOTE}

The final draft was completed while the first author was a Visiting Fellow in the School of Psychology at the University of New South Wales, and supported by a Short Visit Grant from the Royal Society. We thank Kate Bull for conversations that motivated this research, and Ben Newell for encouragement in its implementation. Correspondence concerning this article should be addressed to T. Rakow, Department of Psychology, University of Essex, Colchester CO4 3SQ, England (e-mail: timrakow@ essex.ac.uk)

\section{REFERENCES}

Anderson, N. H., \& Shanteau, J. C. (1970). Information integration in risky decision making. Journal of Experimental Psychology, 84, 441-451.
AYTON, P., \& Fischer, I. (2004). The hot-hand fallacy and the gambler's fallacy: Two faces of subjective randomness? Memory \& Cognition, 32, 1369-1378.

Barron, G., \& Erev, I. (2003). Small feedback-based decisions and their limited correspondence to description-based decisions. Journal of Behavioral Decision Making, 16, 215-233.

Bereby-Meyer, Y., \& EREv, I. (1998). On learning to become a successful loser: A comparison of alternative abstractions of learning processes in the loss domain. Journal of Mathematical Psychology, 42, 266-286.

Biele, G., Rieskamp, J., \& Gonzalez, R. (2009). Computational models for the combination of advice and individual learning. Cognitive Science, 33, 206-242.

Birnbaum, M. H., \& Navarrete, J. B. (1998). Testing descriptive utility theories: Violations of stochastic dominance and cumulative independence. Journal of Risk \& Uncertainty, 17, 49-79.

Bull, C., Yates, R., Sarkar, D., Deanfield, J., \& de Leval, M. (2000). Scientific, ethical, and logistical considerations in introducing a new operation: A retrospective cohort study from paediatric cardiac surgery. British Medical Journal, 320, 1168-1173.

BUSEMEYER, J. R., \& MYUNG, I. J. (1992). An adaptive approach to human decision making: Learning theory, decision theory, and human performance. Journal of Experimental Psychology: General, 121, 177-194.

Busemeyer, J. R., \& Townsend, J. T. (1993). Decision field theory: A dynamic-cognitive approach to decision making in an uncertain environment. Psychological Review, 100, 432-459.

Bush, R. R., \& Mosteller, F. (1955). Stochastic models for learning. Oxford: Wiley.

de Leval, M. R., François, K., Bull, C., Brawn, W., \& SpiegelhalTER, D. (1994). Analysis of a cluster of surgical failures: Application to a series of neonatal arterial switch operations. Journal of Thoracic \& Cardiovascular Surgery, 107, 914-924.

DenRell, J., \& MARCH, J. G. (2001). Adaptation as information restriction: The hot stove effect. Organization Science, 12, 523-538.

Ebbeson, E. B., \& KoneCni, V. J. (1975). Decision making and information integration in the courts: The setting of bail. Journal of Personality \& Social Psychology, 32, 805-821.

EREv, I., \& BARRON, G. (2005). On adaptation, maximization, and reinforcement learning among cognitive strategies. Psychological Review, 112, 912-931.

Fantino, E., \& Esfandiari, A. (2002). Probability matching: Encouraging optimal responding in humans. Canadian Journal of Experimental Psychology, 56, 58-63.

Friedman, D., \& Massaro, D. W. (1998). Understanding variability in binary and continuous choice. Psychonomic Bulletin \& Review, 5, 370-389.

Gaissmaier, W., \& Schooler, L. J. (2008). The smart potential behind probability matching. Cognition, 109, 416-422.

Gaissmaier, W., Schooler, L. J., \& Rieskamp, J. (2006). Simple predictions fueled by capacity limitations: When are they successful? Journal of Experimental Psychology: Learning, Memory, \& Cognition, 32, 966-982.

Gilovich, T., Vallone, R. P., \& TVersky, A. (1985). The hot hand in basketball: On the misperception of random sequences. Cognitive Psychology, 17, 295-314.

GonZalez-VAllejo, C. (2002). Making trade-offs: A probabilistic and context-sensitive model of choice behavior. Psychological Review, 109, 137-155.

Goodnow, J. J. (1955). Determinants of choice-distribution in twochoice situations. American Journal of Psychology, 68, 106-116.

Harvey, N., \& Fischer, I. (1997). Taking advice: Accepting help, improving judgment, and sharing responsibility. Organizational Behavior \& Human Decision Processes, 70, 117-133.

Hau, R., Pleskac, T. J., Kiefer, J., \& Hertwig, R. (2008). The description-experience gap in risky choice: The influence of sample size and experienced probabilities. Journal of Behavioral Decision Making, 21, 493-518.

Hertwig, R., Barron, G., Weber, E. U., \& Erev, I. (2004). Decisions from experience and the effect of rare events in risky choice. Psychological Science, 15, 534-539.

Hogarth, R. M., \& EINHORN, H. J. (1992). Order effects in belief updating: The belief-adjustment model. Cognitive Psychology, 24, 1-55. 
Humphreys, L. G. (1939). Acquisition and extinction of verbal expectations in a situation analogous to conditioning. Journal of Experimental Psychology, 25, 294-301.

Jessup, R. K., Bishara, A. J., \& Busemeyer, J. R. (2008). Feedback produces divergence from prospect theory in descriptive choice. Psychological Science, 19, 1015-1021.

Kahneman, D., \& TVERSKy, A. (1979). Prospect theory: An analysis of decisions under risk. Econometrica, 47, 263-291.

Kareev, Y., Lieberman, I., \& LeV, M. (1997). Through a narrow window: Sample size and the perception of correlation. Journal of Experimental Psychology: General, 126, 278-287.

KATz, L. (1964). Effects of differential monetary gain and loss on sequential two-choice behavior. Journal of Experimental Psychology, 68, 245-249.

Keren, G., \& LewIS, C. (1994). The two fallacies of gamblers: Type I and Type II. Organizational Behavior \& Human Decision Processes 60, 75-89.

Kunadian, B., Dunning, J., Roberts, A. P., Morley, R., Twomey, D., Hall, J. A., ET AL. (2008). Cumulative funnel plots for the early detection of interoperator variation: Retrospective database analysis of observed versus predicted results of percutaneous coronary intervention. British Medical Journal, 336, 931-934. doi:10.1136/ bmj.39512.529120.BE

Luria, A. R. (1987). The mind of a mnemonist. Cambridge, MA: Harvard University Press. (Original work published 1968)

Myers, J. L., \& SADLER, E. (1960). Effects of range of payoffs as a variable in risk taking. Journal of Experimental Psychology, 60, 306-309.

Newell, B. R., Lagnado, D. A., \& Shanks, D. R. (2007). Straight choices: The psychology of decision making. New York: Psychology Press.

NeWELl, B. R., \& RAKOW, T. (2007). The role of experience in decisions from description. Psychonomic Bulletin \& Review, 14, 1133-1139.

Peterson, C. R., \& Ulehla, Z. J. (1965). Sequential patterns and maximizing. Journal of Experimental Psychology, 69, 1-4.

Rakow, T., Demes, K. A., \& Newell, B. R. (2008). Biased samples not mode of presentation: Re-examining the apparent underweighting of rare events in experience-based choice. Organizational Behavior \& Human Decision Processes, 106, 168-179.

RAKow, T., \& RAHIM, S. B. (in press). Developmental insights into experience-based decision making. Journal of Behavioral Decision Making.

Rescorla, R. A., \& Wagner, A. R. (1972). A theory of Pavlovian conditioning: Variations in the effectiveness of reinforcement and nonreinforcement. In A. H. Black \& W. F. Prokasy (Eds.), Classical conditioning II: Current theory and research (pp. 64-99). New York: Appleton-Century-Crofts.

SARIN, R., \& VAHID, F. (2001). Predicting how people play games: A simple dynamic model of choice. Games \& Economic Behavior, 34, 104-122.

Schooler, L. J., \& Hertwig, R. (2005). How forgetting aids heuristic inference. Psychological Review, 112, 610-628.

Shanks, D. R., Tunney, R. J., \& McCarthy, J. D. (2002). A reexamination of probability matching and rational choice. Journal of Behavioral Decision Making, 15, 233-250.
SHARPE, W. F. (1964). Capital asset prices: A theory of market equilibrium under conditions of risk. Journal of Finance, 19, 425-442.

SNiEZEK, J. A., \& BuCKLey, T. (1995). Cueing and cognitive conflict in judge-advisor decision making. Organizational Behavior \& Human Decision Processes, 62, 159-174.

TVERSKY, A., \& EDWARDS, W. (1966). Information versus reward in binary choices. Journal of Experimental Psychology, 71, 680-683.

Weber, E. U., Shafir, S., \& Blais, A.-R. (2004). Predicting risk sensitivity in humans and lower animals: Risk as variance or coefficient of variation. Psychological Review, 111, 430-445.

Wolford, G., Newman, S. E., Miller, M. B., \& Wig, G. S. (2004). Searching for patterns in random sequences. Canadian Journal of Experimental Psychology, 58, 221-228.

YANIV, I. (2004). Receiving other people's advice: Influence and benefit. Organizational Behavior \& Human Decision Processes, 93, $1-13$.

YANIV, I., \& KLeInberger, E. (2000). Advice taking in decision making: Egocentric discounting and reputation formation. Organizational Behavior \& Human Decision Processes, 83, 260-281.

Yechiam, E., \& Busemeyer, J. R. (2005). Comparison of basic assumptions embedded in learning models for experience-based decision making. Psychonomic Bulletin \& Review, 12, 387-402.

Yechiam, E., \& Busemeyer, J. R. (2006). The effect of foregone payoffs on underweighting small probability events. Journal of Behavioral Decision Making, 19, 1-16.

\section{NOTES}

1. The fact that participants do not always pick the better option represents a violation of stochastic dominance in Games 1-3. However, since participants were cued to the possibility of changing payoffs and may have switched between options in the belief that payoffs had changed, this violation is not irrational. Moreover, there is no guarantee that all participants would have experienced win probabilities that reflected the "true" direction of dominance for these two options.

2. B-M models provided a less adequate fit to the data from Experiment 2. For the experience-only condition, the optimal $\lambda$ of .07 for the B-M model generated correlation $(r)$ between expected and observed NS option proportions ranged from .16 to .64. For the experience-plushistory condition, with $\lambda=.11$, the equivalent correlations ranged from 36 to .66 . The lower values of $\lambda$ compared with those in Experiment 1 reflect lower responsiveness to the reward on the most recent trial. Our discussion above identifies three factors that probably contributed to inferior adaptation to the environment in Experiment 2. First, participants had fewer trials in which to learn about the environment. Second, a higher proportion of the games had option payouts that differed, making comparisons between options harder. Third, we strongly suspect that our high-school participants were less well motivated than our participants in Experiment 1, who came from a more standard participant pool and were recruited individually rather than as a group.

(Manuscript received November 16, 2008; revision accepted for publication May 7, 2009.) 